March 2018

\title{
Interprofessional interactions influence nurses' adoption of handover improvement
}

Kimberley Coleman

Epworth Deakin Centre for Clinical Nursing Research, Richmond, Vic, Australia, et60@acorn.org.au

Bernice Redley

Epworth Deakin Centre for Clinical Nursing Research, Richmond, Vic, Australia, et61@acorn.org.au

Beverley Wood

Epworth Deakin Centre for Clinical Nursing Research, Richmond, Vic, Australia, et62@acorn.org.au

Tracey Bucknall

School of Nursing and Midwifery, Deakin University \& Foundational Chair of Clinical Nursing, Alfred Health, Melbourne, Vic, Australia, et63@acorn.org.au

Mari Botti

Epworth Deakin Centre for Clinical Nursing Research, Richmond, Vic, Australia, et64@acorn.org.au

Follow this and additional works at: http://demo.acorn.bepress.com/jpr

Part of the Health Services Administration Commons, Health Services Research Commons, Perioperative, Operating Room and Surgical Nursing Commons, and the Surgery Commons

\section{Recommended Citation}

Coleman, Kimberley; Redley, Bernice; Wood, Beverley; Bucknall, Tracey; and Botti, Mari (2018) "Interprofessional interactions influence nurses' adoption of handover improvement," Journal of Perioperative Nursing: Vol. 28 : Iss. 1 , Article 1.

Available at: http://demo.acorn.bepress.com/jpr/vol28/iss1/1 


\title{
PEER-REVIEWED ARTICLE
}

\section{Interprofessional interactions influence nurses' adoption of handover improvement}

\author{
Kimberley Coleman • RN, BN (Hons), Grad Dip Nurs Prac (Periop) \\ Research Fellow, Epworth Deakin Centre for Clinical Nursing Research, Richmond, Vic, Australia \\ Bernice Redley • RN, BN (Hons), PhD \\ Associate Professor, Epworth Deakin Centre for Clinical Nursing Research, Richmond, Vic, Australia \\ Beverley Wood • RN, BAppSci (Adv Nsg-Ed), MEdSt, PhD, FACN \\ Research Fellow, Epworth Deakin Centre for Clinical Nursing Research, Richmond, Vic, Australia
}

Tracey Bucknall • RN, BN, Grad Dip Adv Nurs, PhD

Associate Head of School (Research), School of Nursing and Midwifery, Deakin University \& Foundational Chair of Clinical Nursing, Alfred Health, Melbourne, Vic, Australia

Mari Botti • RN, PhD

Alfred Deakin Professor and Chair in Nursing, Epworth Deakin Centre for Clinical Nursing Research, Richmond, Vic, Australia

\section{Corresponding author}

Kimberley Coleman, RN, BN (Hons), Grad Dip Nurs Prac (Periop)

Research Fellow, Deakin-Epworth Centre for Clinical Nursing Research, 185-187 Hoddle Street, Richmond, Vic 3121, Australia

Tel: (03) 94266565 Mobile: 0407593150 email: Kimberley.coleman1@deakin.edu.au

Abstract

Aim: The purpose of this study was to explore clinician experiences of adopting quality improvement tools to standardise interprofessional (anaesthetist-to-nurse) handover communication when patients arrive in the post-anaesthetic care unit (PACU).

Method: In this study, factors that impacted PACU nurses' adoption of the quality improvement tools were explored using pre- and postimplementation, semi-structured focus group interviews. Interview data was analysed using the PARiHS ${ }^{1}$ (context, evidence and facilitation) framework as a deductive analysis tool.

Results: PACU nurses recognised that PACU handover from anaesthetists to PACU nurses was suboptimal and described the tools as useful for their practice. However, PACU nurses frequently cited fear of anaesthetists' reactions as reasons not to insist on the use of the handover improvement tools. PACU nurses at Hospital 2 identified lacking "authority" (Hospital 2 FG 2) in the OR as hindering their willingness to use the tools against these behaviours. In comparison, visible support from leadership at Hospital 1 was described as encouraging nurses to be "assertive" (Hospital 1 FG 2) and take charge of their patients' care.

Conclusion: PACU nurses perceived the handover tools were useful and helped them identify gaps in handover practice; however, PACU nurses described difficult relationships as hindering communication effectiveness and discouraging their adoption of the tools. However, strong leadership and organisational support of change emerged as essential to mitigate the effects of these difficult relationships.

\section{Keywords}

Post-anaesthesia care units, clinical handover, quality improvement, interprofessional relations, communication.

\section{Introduction}

Using standardised clinical handover processes is recommended to improve communication effectiveness and mitigate risk for handover miscommunication at transitions in care, including in perioperative settings ${ }^{2}$. To date, effective and sustainable handover solutions specific for interdisciplinary handover in perioperative settings have been elusive.

Successful quality improvement requires tailored approaches and strategic engagement with clinicians ${ }^{3-6}$. Studies of patient safety through transitions in care show nurses' constant bedside presence with acute and vulnerable patients across all care types means they must assume responsibility for continuity of patient care and patient safety across care transitions involving other disciplines ${ }^{7,8}$. In Australian private hospitals, nurses provide the only permanent staff workforce in perioperative settings as anaesthetists and surgeons usually work intermittently. As such, nurse engagement is critical for the success and sustainability of initiatives to enhance interdisciplinary handover and patient safety across transitions within perioperative settings. 
In this paper we report findings from a qualitative study that explored nurses' experiences of adopting quality improvement tools intended to standardise interdisciplinary handover from the operating theatre into the post-anaesthetic care unit (PACU) in two private hospital settings. The study was part of a larger, longitudinal program of research seeking to improve the quality and safety of patient care by standardising interdisciplinary handover communication on patient transition into the PACU that followed initial work funded by the Australian Commission on Safety and Quality in Health Care's National Clinical Handover pilot program ${ }^{9-11}$. This paper reports early findings related to implementation by exploring clinician adoption of the handover improvement tools developed in the earlier study. The findings of this study provide insights into the complex clinician and system interactions that influenced nurses' adoption of the standardised interdisciplinary handover practices.

\section{Background}

Communication failures are a significant contributor to preventable adverse events and iatrogenic harm to patients in hospitals; particularly in perioperative settings ${ }^{12-14}$. Patient handover is the most frequent form of clinical communication in hospitals and a wellrecognised source of risk to patient safety ${ }^{11}$. In the PACU, risk for handover communication error is increased by high patient turnover, the high cognitive load for clinicians who are caring for complex, sick and vulnerable patients, environmental distractions and professional differences between anaesthetists and PACU nurses in their expectations, attitudes, communication styles and prioritisation of patient information during handover ${ }^{9-11,15,16}$. Standardised clinical handover has been proposed as an effective solution to mitigate risks associated with handover miscommunication in $\mathrm{PACU}^{2,11}$.

Compared to public hospitals, Australian private hospitals present distinct challenges for both handover communication and quality improvement due to the unique relationships between the organisation, medical professionals and the patient ${ }^{10}$. In this context, anaesthetists and surgeons may work intermittently and across multiple hospitals; they are often viewed as customers or contractors of the hospital service rather than employees; a relationship with potential to exacerbate nurses' perceptions of professional hierarchies and power imbalance between disciplines. These factors are well known to adversely affect interdisciplinary communication ${ }^{17,18}$.

As a result of the anaesthetic and surgeon roles, nurses are the health care professionals that provide continuous clinical surveillance of patients, hence are integral to drive change in interdisciplinary handover behaviours ${ }^{7}$. Research shows, however, that nurses are often reluctant to influence practice in their workplace ${ }^{19,20}$ due to complex contextual, environmental and interpersonal factors ${ }^{16,21}$. Few studies are available to guide methods to implement and sustain handover quality improvement strategies in complex acute clinical settings such as the PACU ${ }^{7,10,22}$ and none have specifically addressed the Australian private hospital sector. Research examining interdisciplinary handover communication in the PACUs is scarce ${ }^{8}$ and PACU nurses' unique perspectives of implementing quality improvement of interdisciplinary handover communication has not been examined.

\section{Research questions}

This study was guided by two research questions:
1. What were PACU nurses' experiences of adopting tools to standardise PACU handover?

2. What influenced their adoption of the tools into their clinical practice?

\section{Method}

A naturalistic, descriptive design with pre and post measures was used to explore nurses' experiences of anaesthetist-to-nurse PACU handover and implementation of improvement tools. The study was conducted at two private hospitals located in metropolitan Melbourne; both had participated in earlier stages of the research and had agreed to adopt the tools to standardise handover into their PACU. These tools consisted of: a "COLD" process tool (Connect, Observe, Listen, Delegate), the "ISoBAR" handover content tool and a 10-point safety checklist (Table 1) to ensure transfer of information at handover was complete $e^{10,11}$.

The implementation strategy was guided by the theory of "Promoting Action on Research Implementation in Health Services" (PARiHS) and knowledge-to-action (KTA) models ${ }^{1,3,6}$. Implementation was

\section{Table 1: Process of PACU handover}

\begin{tabular}{lc} 
Connect equipment & - Immediately connect oxygen and monitoring as required \\
\hline Observe patient safety & - Identify and respond to any immediate patient care needs \\
\hline Listen to the handover & - Stop activities to listen, e.g. 'time in' \\
& - Content of the verbal handover uses ISOBAR format: \\
& $-\quad$ Identify (introduce self, identify patient and \\
& $-\quad$ important information); \\
& $-\quad$ Observations (normal or abnormal vital signs), \\
& $-\quad$ Background (relevant history and allergies); \\
& $-\quad$ Assessment (patient progress and status); \\
& $-\quad$ Recommendations (what needs to be done, how, \\
& Use interpersonal interactions during delivery of verbal \\
information (receptiveness, eye contact, engagement, \\
affirming gestures)
\end{tabular}

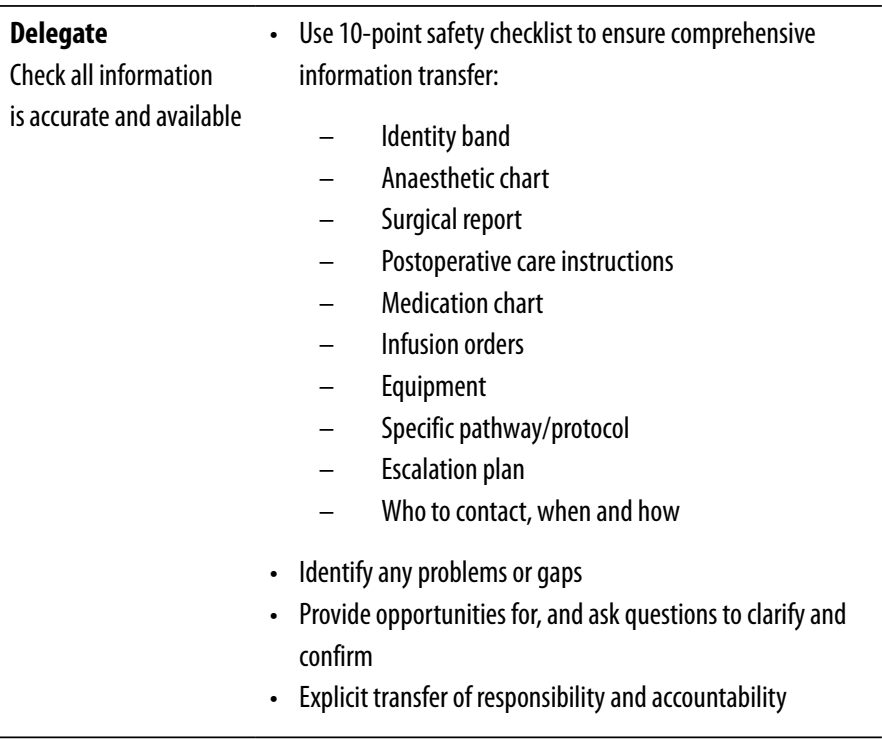


Table 2: Focus group participants

\begin{tabular}{lcc}
\hline Site & Focus group number & Number of participants \\
\hline Hospital 1 & Focus group 1 & 6 \\
\hline Hospital 2 & Focus group 2 & 6 \\
\hline & Focus group 1 & 2 \\
\hline
\end{tabular}

led at each hospital by a trained 'clinical champion' who was an experienced front-line clinician that provided 'real time' education for other staff, as well as supported adoption by role modelling use of the tools for their colleagues and promoting their continued use ${ }^{10}$.

Ethics approval was obtained at both hospitals and the affiliated university. Two focus group interviews were conducted at each site. Participants were 17 nurses who worked on the permanent roster in the PACU for at least two shifts per week (Table 2). The first focus groups were held prior to introduction of the PACU handover improvement tools and the second were held between three and five months after implementation to allow for uptake of the tools.

Semi-structured questions were used to guide the focus groups. Focus group discussions were audio-taped, transcribed verbatim and de-identified for analysis. Transcripts were analysed independently by two researchers using the qualitative framework method ${ }^{4}$ that was informed by the three key concepts of the PARiHS model for guiding implementation of evidence-based practice: 'Evidence', which refers to the sources of knowledge that guide clinicians' practice including research or training, and knowledge gained from practical experiences; 'Context' is described as the quality of the environment or setting in which health care is taking place or research is being implemented into practice and; 'Facilitation' which refers to the external and internal processes that inspire and guide the process of change ${ }^{1}$.

\section{Results and discussion}

Overall, the handover improvement tools were perceived as being well suited to PACU, the nurses' needs and as filling a gap in current practice; suggesting support for the adoption of the handover practice improvement ${ }^{7,22}$. Despite this finding, participants reported different perceptions of their adoption and plan for ongoing use of the handover tools at the two hospitals. PACU nurses at Hospital 1 reported they had adopted the handover improvement tools and planned to maintain their use. Alternatively, PACU nurses at Hospital 2 reported limited use of the tools and a reluctance to adopt them into their practice, despite seeing merit for their use in practice improvement.

\section{Handover improvement tools provided EVIDENCE for the PACU practice improvement}

Prior to implementation of the PACU handover improvement tools, PACU nurses reported previous clinical experience was the dominant form of evidence they used to guide their handover practices. In the post-implementation focus groups, PACU nurses reported the handover improvement tools provided them with a useful source of knowledge about desirable handover practices, even when their previous practices persisted. Nurses' exposure to the PACU handover improvement tools appeared to influence their expectations of handover.
Pre-implementation, participants identified potentially risky handover practices. They described PACU handover as "rushed" (Hospital 2 FG1) and "dangerous" (Hospital 1 FG1). Handover processes were described as informal and characterised by anaesthetists rapidly reciting information "by memory" (Hospital 2 FG 1). PACU nurses at both hospitals reported using time-consuming practices such as searching through patient notes to mitigate gaps in PACU handover information rather than asking questions at the time of handover. Interestingly, at the pre-implementation focus groups PACU nurses did not link such practices to increased patient risk.

Overall, during the post-implementation focus groups, PACU nurses reported exposure to the handover improvement tools provided useful evidence for their practice, assisted them to identify gaps in their handover practices.

While PACU nurses at Hospital 2 reported perceptions that handover had "not changed" (Hospital 2 FG 2) after introduction of the tools; participants at both sites identified potential patient safety risks associated with their handover practices that had been highlighted to them by the handover tools. For example, PACU nurses reflected that: anaesthetists "hand-over as they're wheeling [patients] through the door" (Hospital 2 FG 2); they were distracted trying to "observe the patient" (Hospital 1 FG 2) during the anaesthetists' verbal handover; and "doing everything at once" (Hospital 2 FG 2). These findings suggested nurses recognised the importance of reducing distractions or interruptions by using a 'time-in' (stop to listen) during the verbal handover as specified in the PACU handover tools. Participants at Hospital 1 reported a change in practice where nurses were "helping other staff to make sure that the person that's actually receiving the handover can focus on what's being said" (Hospital 1 FG 2) facilitating a 'time-in' for handover.

In addition, participants also described a range of consequences of poor handover performance and compensatory practices they had adopted that often led to delays in care delivery. For example, PACU nurses reported "leaving the room all the time to chase stuff up" (Hospital 2 FG2); having to go "back and forth from the anaesthetist and the surgeon" (Hospital 2 FG 2); and calling a surgeon where "no orders [were] written" (Hospital 1 FG2) or the documents necessary for care delivery were not provided at handover into the PACU. Such documents were often a pre-requirement for the patient to leave the PACU and their absence at handover on arrival to the PACU created unnecessary extra work for the PACU nurse to locate them. PACU nurses reflected that many of these time-consuming practices were "entirely avoidable" (Hospital 2 FG 2) if high-quality handover practice and checklists were adhered to. In addition, participants perceived these events to negatively affect the quality of patient care.

\section{Workplace CONTEXT influenced adoption of the handover improvement tools}

Consistent with the PARiHS framework used for analyses, workplace CONTEXT emerged as an important influence on PACU nurses' adoption the PACU handover improvement tools and, hence, the success of implementation.

In the focus groups at both hospital sites, PACU nurses reported feelings of being intimidated by anaesthetists' behaviours and "moods" (Hospital 1 FG 2); experiencing difficult interactions with some anaesthetists on speaking up about poor handover practices 
that "make our working relationship [with anaesthetists] strained and difficult in the future" (Hospital 2 FG 2); encounters with anaesthetists that don't like "being told what to do" (Hospital 2 FG 2 ); and fear that anaesthetists would "take it personally" (Hospital 2 FG 2) if they addressed poor practices. PACU nurses also expressed fear of punitive action from anaesthetists. They described situations where the anaesthetist would "react" (Hospital 1 FG 1) angrily if the nurses were perceived to be asking "too many" questions (Hospital 1 FG 1). Frequent intimidation and inappropriate anger are commonly described as 'disruptive behaviours' and are known to impede interdisciplinary communication, hinder the relay of information, increase staff stress, undermine morale and adversely affect patient safety ${ }^{23,24}$.

Participants described a range of ways that anaesthetists' attitudes influenced their handover performance. PACU nurses at Hospital 1 most often expressed their reluctance to adopt the PACU handover improvement tools as a direct consequence of interactions with some anaesthetists displaying 'disruptive behaviours' as exemplified in the following comment:

I try to follow [the handover tools] but then of course you've got that anaesthetist showing that mood in front of you. (Hospital 1 FG 2)

One nurse reported she was "ignored quite a few times" when asking for time to connect monitors prior to commencing verbal handover (Hospital 1 FG 2).

PACU nurses at both hospitals reported they avoided asking anaesthetists any questions during handovers as this required them to be "assertive" (Hospital 1 FG 2); this was despite their recognition of the necessity to ask questions to ensure they had sufficient information to care for their patients ${ }^{25}$. One PACU nurse described feeling uneasy when an anaesthetist used the handover improvement tools as a joke as illustrated by the following:

[One anaesthetist] will put on a really fake American accent and take it right to the nth degree, introduce himself, almost full name, middle name, surname and patient's full details. ... he's taking the piss when he does it, but you still get the information that you're looking for. (Hospital 2 FG 1)

Contextual influences emerged differently at the two hospitals, which may be explained in part by exploring PACU nurses' perceptions of the organisational facilitation for the adoption of the PACU handover improvement tools at their hospital.

\section{Explicit organisational support FACILITATED adoption of tools}

Differences between hospitals emerged in PACU nurses' experiences of facilitation to adopt the PACU handover improvement tools. In the post-implementation focus group, PACU nurses at Hospital 1 reported the handover improvement tools had "been introduced quite well and people have taken [them] on board" (Hospital 1 FG 2). In contrast, PACU nurses at Hospital 2 described poor awareness of the PACU handover tools in their department and reported that handover practices had not changed as a result of implementation. Analyses of the facilitation for implementation revealed the role of leadership was possibly a major influence on the success of implementation.
PACU nurses at Hospital 1 described the important roles of local leaders to facilitate implementation of the PACU handover improvement tools. These included reminders, support for education of staff and communicating the organisation's plan to support adoption of the PACU handover improvement tools into practice. Communication processes via "under the clock meeting[s]" and "a write-up in the communications book in recovery" in addition to "one-on-one" education by the 'clinical champion' and other leaders (Hospital 1 FG 2) were identified as successful strategies that raised their awareness of the tools and the implementation strategy. Despite expressing fears about being assertive and questioning anaesthetists, PACU nurses at Hospital 1 reported feeling supported and empowered by their management to take actions to use the tools. These findings highlight the key influence of local leaders to effectively communicate the organisational goals of quality improvement to ensure staff felt supported to use the handover improvement tools ${ }^{10,17}$. Similar to previous study, nurses' perceptions of explicit organisational and manager support emerged as a possible facilitator to the adoption of the new practices, despite the challenges experienced $^{17,21}$

Alternatively, PACU nurses at Hospital 2 reported their reluctance to use the tools and attributed their reluctance to perceptions there was a lack of "a strong voice in the theatre complex" (Hospital 2 FG 2) for PACU nurses and the absence of any clear, explicit support from their managers.

There is no way in Hades that I would implement this until I had a direct message from my manager that this was to occur ... (Hospital 2 FG 2)

Furthermore, PACU nurses at Hospital 2 also reported feeling they did not have sufficient "authority" (Hospital 2 FG 2) to challenge anaesthetists, adopt the handover improvement tools, or initiate change to PACU handover practice in their workplace. They reported a fear of "punishment" or reprimands from management if they caused difficulty with anaesthetists, even if this was in the best interests of their patients. For example, one participant recounted their experience where management had failed to act in response to concerns raised about an anaesthetist's practice: "the anaesthetist has apparently been asked not to do it and then done it again, so what do we do from there?" (Hospital 2 FG 2).

PACU nurses at Hospital 2 reported limited overall awareness of the tools in their department; they hadn't "seen any promotion" of the tools and had not "seen the educators come around and educate" (Hospital 2 FG 2) and as a result had perceived that support for tool implementation by leadership was absent. When combined with a perceived elevated standing of surgeons and anaesthetists within the organisation where "doctors are still viewed as clients" (Hospital 2 FG 2), PACU nurses were reluctant to adopt the handover improvement tools, despite their views they were useful for practice. Similarly, literature also suggests nurses' failure to engage in quality improvement strategies may be attributed to demoralisation and perceived inequity ${ }^{26,27}$. Lack of nurse authority and poor cooperation from medical staff are further barriers to research utilisation and implementing best practice ${ }^{20}$.

Important limitations of this study include the small number of sites and participants and the specific focus on the private sector only. 
Although the participants may not be representative of the sites or broader public hospital sector, the findings provide important insights that can be used to direct future research.

\section{Conclusion}

In this study, PACU nurses acknowledged the handover improvement tools were well suited to their workplace and their needs; but some nurses were reluctant to adopt the tools into their clinical practice. The findings of this study suggest visible leadership and explicit organisational support were key facilitators to support nurses as they manage the many challenges encountered when adopting change. Barriers such as perceptions of hierarchical relationships and disruptive behaviours were identified as risks to effective interdisciplinary communication and the successful adoption of PACU handover improvement tools. The role of effective frontline leadership to help nurses mitigate barriers to change has broader implications for effective implementation of quality improvement in clinical environments, and hence is worthy of further research. In addition, this study supports a need for future research to explore the potential for handover communication tools to improve interprofessional relationships and patient safety outcomes.

\section{Acknowledgement}

Our project was funded by a Deakin University, Quality and Patient Safety Research Grant.

\section{References}

1. Rycroft-Malone J (2004). The PARiHS framework - a framework for guiding the implementation of evidence-based practice ... Promoting Action on Research Implementation in Health Services. Journal of Nursing Care Quality, Vol. 19, No. 4, pp. 297-304.

2. Manser T \& Foster S (2011). Effective handover communication: An overview of research and improvement efforts. Best Practice \& Research Clinical Anaesthesiology, Vol. 21, pp. 181-91.

3. Canadian Institute of Health Research. KT Knowledge Base 2011 [7/10/2012]. Available from: http://ktclearinghouse.ca/knowledgebase/ knowledgetoaction/action.

4. Dawes M, Davies P, Gray A, Mant J, Seers K \& Snowball R (2005). Evidence-Based Practice. A Primer for Health Professionals. 2nd ed. Edinburgh: Elsevier Churchill Livingston.

5. Greenfield D, Nugus P, Travaglia J \& Braithwaite J (2011). Factors that shape the development of interprofessional improvement initiatives in health organisations. British Medical Journal Quality and Safety, Vol. 20, No. 4, pp. 332-7.

6. Graham ID, Logan J, Harrison MB, Straus SE, Tetroe J, Caswell W et al. (2006). Lost in knowledge translation: Time for a map? Journal of Continuing Education in the Health Professions, Vol. 26, No. 1, pp. $13-24$.

7. Thomas L \& Donohue-Porter P (2012). Blending evidence and innovation: improving intershift handoffs in a multihospital setting. Journal of Nursing Care Quality, Vol. 27, No. 2, pp. 116-24.

8. Smith AF, Pope C, Goodwin D \& Mort M (2008). Interprofessional handover and patient safety in anaesthesia: observational study of handovers in the recovery room. British Journal Of Anaesthesia, Vol. 101, No. 3, pp. 332-7.

9. Botti M, Bucknall T, Cameron P, Johnstone M-J, Redley B, Evans S et al. (2009). Examining communication and team performance during clinical handover in a complex environment: the private sector post-anaesthetic care unit. Medical Journal of Australia, Vol. 190, No. 11, S157-S60.
10. Botti M, Bucknall T, Cameron P, Johnstone M-J, Redley B, Evans S et al. (2009). Inter-professional communication and team climate in complex clinical handover situations: issues for patient safety in the private sector. Burwood: Deakin University \& Monash University.

11. Australian Commission on Safety and Quality in Health Care (2011). External Evaluation of the National Clinical Handover Initiative Pilot Program Final Report Sydney: ACSQHC. [cited 8 December 2014]. Available from: http://www.safetyandquality.gov.au/wp-content/ uploads/2012/02/National-Clinical-Handover-Initiative-Pilot-ProgramEvaluation-Final-Report-Website-Ready-Version-February-20111.pdf.

12. Agarwal HS, Saville BR, Slayton JM, Donahue BS, Daves S, Christian $\mathrm{KG}$ et al. (2012). Standardized postoperative handover process improves outcomes in the intensive care unit: A model for operational sustainability and improved team performance*. Critical Care Medicine, Vol. 40, No. 7, pp. 2109-15.

13. Australian Institute of Health and Welfare, Australian Commission on Safety and Quality in Health Care (2007). Sentinel events in Australian public hospitals 2004-05. [cited 3 October 2012]. Available from: http:// www.aihw.gov.au/WorkArea/DownloadAsset.aspx?id=6442456851.

14. The Joint Commission (2012). Sentinel Event Data Root Causes by Event Type 2004-1Q. [cited 3 October 2012]. Available from: http://www. jointcommission.org/assets/1/18/Root_Causes_by_Event_Type_2004 1Q2012.pdf.

15. Nagpal K, Abboudi M, Fischler L, Schmidt T, Vats A, Manchanda C et al. (2011). Evaluation of Postoperative Handover Using a Tool to Assess Information Transfer and Teamwork. Annals Of Surgery, Vol. 253, No. 4 , pp. 831-7.

16. Lingard L, Whyte S, Espin S, Ross Baker G, Orser B \& Doran D (2006). Towards safer interprofessional communication: Constructing a model of "utility" from preoperative team briefings. Journal of Interprofessional Care, Vol. 20, No. 5, pp. 471-83.

17. McMurray A, Chaboyer W, Wallis M \& Fetherston C (2010). Implementing bedside handover: strategies for change management. Journal of Clinical Nursing, Vol. 19, No. 17/18, pp. 2580-9.

18. Riesenberg LA, Leisch J \& Cunningham JM (2010). Nursing Handoffs: A Systematic Review of the Literature. AJN The American Journal of Nursing, Vol. 110, No. 4, pp. 24-34 10.1097/01. NAJ.0000370154.79857.09.

19. Attree M (2007). Factors influencing nurses' decisions to raise concerns about care quality. Journal of Nursing Management, Vol. 15, No. 4, pp. 392-402.

20. Hutchinson AM \& Johnston L (2004). Bridging the divide: a survey of nurses' opinions regarding barriers to, and facilitators of, research utilization in the practice setting. Journal of Clinical Nursing, Vol. 13, No. 3, pp. 304-15.

21. Fourcade A, Blache J-L, Grenier C, Bourgain J-L \& Minvielle E (2012). Barriers to staff adoption of a surgical safety checklist. Quality and Safety in Healthcare, Vol. 21, pp. 191-7.

22. Hedges CC, Nichols A \& Filoteo L (2012). Relationship-based nursing practice: transitioning to a new care delivery model in maternity units. Journal of Perinatal \& Neonatal Nursing, Vol. 26, No. 1, pp. 27-36.

23. Firth-Cozens J (2004). Why communication fails in the operating room Quality \& Safety In Health Care, Vol. 13, No. 5 p. 327.

24. Pfifferling JH (2008). Physicians' "disruptive" behavior: Consequences for medical quality and safety. American Journal of Medical Quality, Vol. 23, No. 3, pp. 165-7.

25. Squire S \& Annells M (2010). Barriers to effective PARU handover. ACORN: the Journal of Perioperative Nursing in Australia, 2010, Vol. 23 , No. 4, p. 16.

26. Leape L, Berwick D, Clancy C, Conway J, Gluck P, Guest J et al. (2009). Transforming healthcare: a safety imperative. Quality \& Safety In Health Care, Vol. 18, No. 6, pp. 424-8.

27. Makary MA, Sexton JB, Freischlag JA, Holzmueller CG, Millman EA, Rowen L et al. (2006). Operating Room Teamwork among Physicians and Nurses: Teamwork in the Eye of the Beholder. Journal of the American College of Surgeons, Vol. 202, No. 5, pp. 746-52. 